\title{
Leishmania donovani promastigotes evade the antimicrobial activity of neutrophil extracellular traps
}

\author{
Christelle Gabriel $^{1 *}$, Robert W McMaster ${ }^{2}$, Denis Girard ${ }^{1}$, Albert Descoteaux ${ }^{2}$ \\ From Institut Pasteur International Network Annual Scientific Meeting \\ Hong Kong. 22-23 November 2010
}

Upon their recruitment to a site of infection and their subsequent activation, neutrophils release DNA and a subset of their granule content to form filamentous structures, known as neutrophil extracellular traps, which capture and kill microorganisms. In this study, we show that Leishmania promastigotes induced the rapid release of neutrophil extracellular traps from human neutrophils and were trapped by these structures. The use of Leishmania mutants defective in the biosynthesis of either lipophosphoglycan or GP63 revealed that these two major surface promastigote virulence determinants were not responsible for inducing the release of neutrophil extracellular traps. We also demonstrate that this induction was independent of superoxide production by neutrophils. Finally, in contrast to wild type $L$. donovani promastigotes, mutants defective in lipophosphoglycan biosynthesis were highly susceptible to the antimicrobial activity of neutrophil extracellular traps. Altogether, our data suggest that neutrophil extracellular traps may contribute to the containment of $L$. donovani promastigotes at the site of inoculation, thereby facilitating their uptake by mononuclear phagocytes.

\section{Author details}

${ }^{1}$ INRS- Institut Armand-Frappier, Laval, Québec, Canada H7V 1B7.

${ }^{2}$ Department of Medical Genetics, University of British Columbia, Vancouver, BC, Canada V6H $3 Z 6$.

Published: 10 January 2011

'INRS- Institut Armand-Frappier, Laval, Québec, Canada H7V 1B7

Full list of author information is available at the end of the article
doi:10.1186/1753-6561-5-S1-P40

Cite this article as: Gabriel et al:: Leishmania donovani promastigotes evade the antimicrobial activity of neutrophil extracellular traps. BMC Proceedings 2011 5(Suppl 1):P40.
Submit your next manuscript to BioMed Central and take full advantage of:

- Convenient online submission

- Thorough peer review

- No space constraints or color figure charges

- Immediate publication on acceptance

- Inclusion in PubMed, CAS, Scopus and Google Scholar

- Research which is freely available for redistribution
() Biomed Central 